\title{
The Three Phase Induction Motor Test using MATLAB 2021b/SIMULINK at Bukit Energi Servis Terpadu, Ltd
}

\author{
Destra Andika Pratama, Masayu Anisah, Kabul Andi Setiyadi
}

\begin{abstract}
The purpose of the paper is to investigate the performance characteristics squirrel-cage induction motor available. This paper discusses determination parameters for three-phase induction motor based on experimental data, which the standard test data is not completely available in the end-users. Alternatively, equivalent circuit parameters should be estimated based on the released performance data of the induction motor. This paper also describes MATLAB 2021b/Simulink implementation of three phases of induction motor testing, which includes the no-load, full load, and locked rotor tests were performed to identify the equivalent circuit parameters. The value calculated of parameters simulation results has been compared to experimental values as verification and validation techniques. The deviation of measured values was diagnosed between $0.13 \%$ and $1.31 \%$.
\end{abstract}

Keywords- MATLAB 2021b, Three Phase IM Equivalent Circuit, DC Test, No-Load Test, Blocked Rotor Test, Electric Motor.

\section{Introduction}

I In essence, each induction motor has different torquespeed characteristics. By knowing the characteristics of a motor, the selection of a motor for driving the load can be made correctly. However, these characteristics can only be known if the motor parameters in question are also known. These parameters include stator resistance, stator leakage reactance, rotor resistance, rotor leakage reactance, magnetization reactance, and iron core resistance. This parameter value will not be found on the nameplate of a motor. It is necessary to test the motor, which includes a noload experiment, a retained rotor experiment, and a DC experiment [1].

Typically a motor can draw about 5 to 7 times the rated current during starting. If the load torque during starting and the motor load inertia is not large, the starting process only takes a short time, so the motor temperature does not exceed the allowable limit. In such applications, the motor can be started directly into the grid, and this is usually reserved for small motors, which is not the case for large motors. If the load torque during starting is high or the load inertia is high, the starting process will take a long time. If the motor draws a large current during starting, it will cause damage to the motor due to overheating. A high starting current can also result in a large voltage drop in the network. Thus the proper starting method needs to be applied to large capacity motors to reduce starting current and voltage drop [2].

- Destra Andika as lecturer on bachelor's degree program in electric engineering department in State Polytechnic of Sriwijaya, Indonesia, Mobile Number: 0816399323. E-mail: destra_andika_pratama@polsri.ac.id.

- Masayu Anisah as lecturer on bachelor's degree program in electric engineering department in State Polytechnic of Sriwijaya, Indonesia. E-mail: masayu_anisah@polsri.ac.id.

- Kabul, Andi are currently pursuing bachelor's degree program in electric engineering department in State Polytechnic of Sriwijaya, Indonesia,

E-mail:kabul.abdullah@bestpower.co.id; andi.setiyadi@bestpower.co.id.
For winding-rotor induction motors, starting at low currents is possible by inserting external resistance in the rotor circuit during starting [3]. This external resistance increases the starting torque and reduces the starting current. For a cage-rotor induction motor, the starting current can vary over a wide range, depending on the nominal power of the motor and the rotor resistance under starting conditions. In comparison, the starting method can be done in the form of star-triangle starter / Y (star-delta starter), autotransformer starter, primary resistor starter, reactor starter, separate coil starter, or solid-state starter [4].

The induction motor equivalent circuit in picture 1(a) shows the equivalent circuit per phase of an induction motor, while picture 1(b) is an alternative equivalent circuit [5].

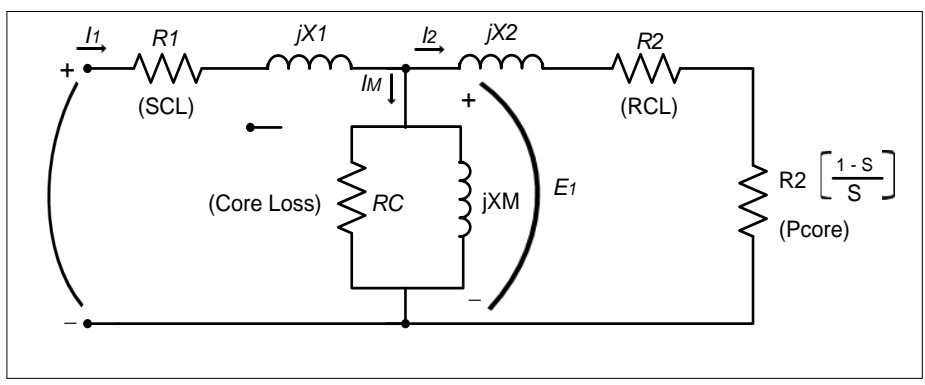

(a)

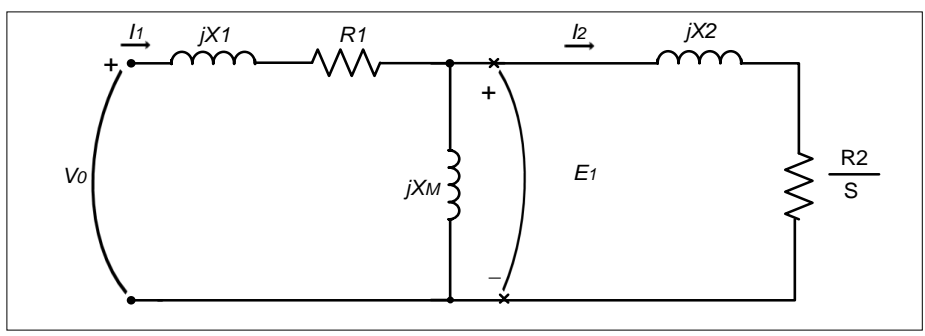

(b)

Picture 1. The equivalent circuit of an induction motor 


\section{Description of the picture:}

$\mathrm{R}_{1}=$ stator resistance

$\mathrm{X}_{1}=$ stator leakage reactance

$\mathrm{R}_{2}=$ rotor resistance refers to the stator

$\mathrm{X}_{2}=$ rotor leakage reactance refers to the stator

$\mathrm{Rc}_{\mathrm{C}}=$ iron core resistance

$\mathrm{X}_{\mathrm{M}}=$ magnetizing reactance

$\mathrm{I} 1=$ stator current

I2 = rotor current refers to the stator

$\mathrm{V} \varnothing=$ source of voltage

$\mathrm{E} 1=$ stator induction voltage

\section{Setup of Experimental Three Test of Induction Motor}

This experiment explores squirrel-cage induction motors (IMs). IMs are widely used in industrial applications [6]. The equivalent circuit for each phase is used to investigate the operating characteristics of induction motors by representing their steady-state, where $R_{1}, X_{1}$ represent resistance and the leakage reactance and of the stator part of the circuit and, $\mathrm{R}_{2}$, $\mathrm{X}_{2}$ represents resistance and the leakage reactance of the rotor of the circuit. Resistance, $R_{c}$, which means core losses, represents magnetization reactance and slip. The purpose of using the equivalent circuit is to facilitate calculations of operating quantities of induction machines $[7,8]$.

\subsection{No Load Test}

No Load Test is intended to measure the magnitude of motor rotation losses and provide information about the magnetization current. The circuit for this experiment is shown in picture 2(a).

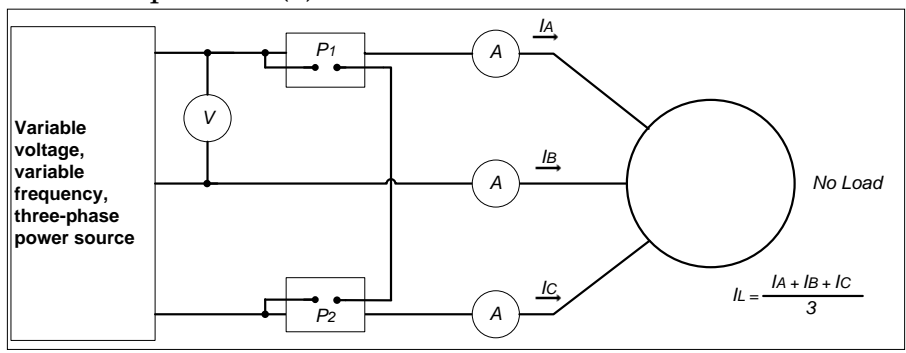

(a)

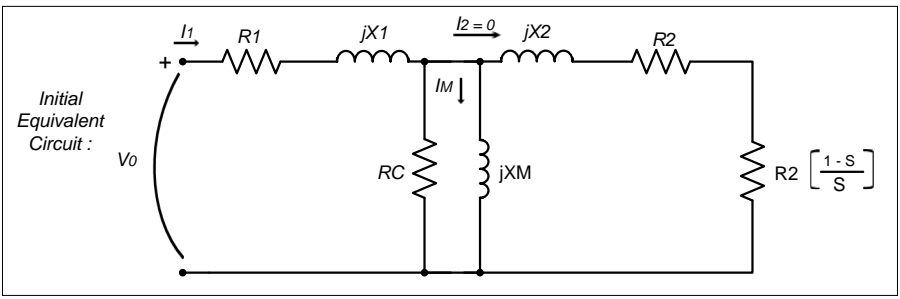

(b)

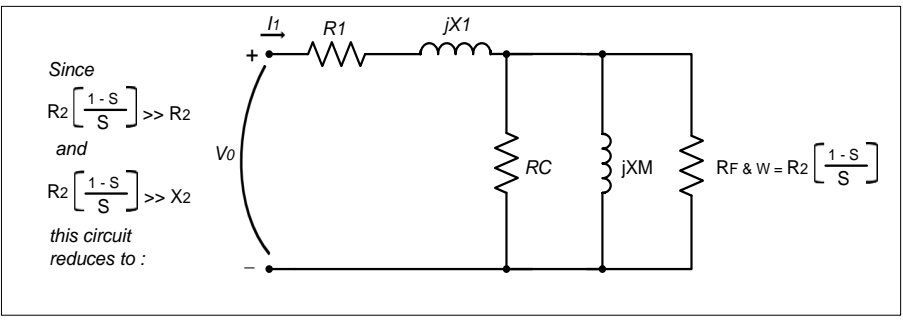

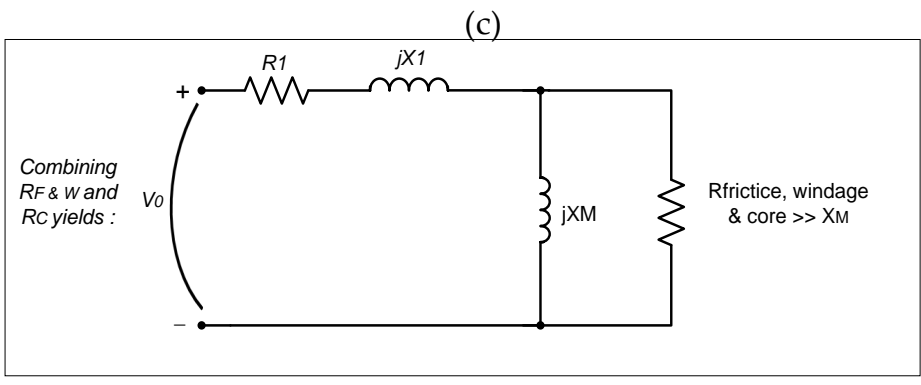

(d)

Picture 2. An experiment of no-load for induction motor

In this experiment, two wattmeters, one voltmeter, and three ammeters are connected to an induction motor. As long as the power supply is connected, the motor will rotate. In this condition, the only motor loads are friction and wind losses $\left(P_{F \& W}\right)$, so that all converted electrical power $\left(P_{c o n v}\right)$ is absorbed as mechanical losses, and the motor slip is very small (possibly around 0.001 or less). The equivalent circuit of this motor is shown in picture $2(b, c, d)$.

With a very small slip value, the value $R_{2}(1-\mathrm{s}) / \mathrm{s}$ is much bigger than $R_{2}$ and much bigger than $X_{2}$. In this case, the equivalent circuit can be approximated to a final circuit, as shown in picture $2(b, c, d)$. In the picture, it can be seen that the output resistance is connected in parallel with the magnetizing reactance $X_{M}$ and core losses $R_{c}$ [9].

In this no-load condition, the input power is measured with measuring instruments whose value should equal the losses on the motor. The rotor copper losses are negligible because the current $I_{2}$ is very small [because the load resistance $R_{2}$ (1$\mathrm{s}) / \mathrm{s}$ is very large]. The stator copper losses in this case are: $P_{S C L}=I_{1}^{2} R_{1}$

so the input power is:

$P_{\text {in }}=P_{\text {sCL }}+P_{\text {core }}+P_{\text {FEW }}+P_{\text {misc }}$

$P_{\text {in }}=3 I_{1}^{2} R_{1}+P_{\text {rot }}$

Where $P_{\text {rot }}$ is the rotational losses of motor:

$P_{\text {rot }}=P_{\text {core }}+P_{\text {FRW }}+P_{\text {mise }}$

So, the engine speed losses can be determined by providing power to the motor. The equivalent circuit describing the operation of the motor under these conditions contains a resistance $R_{c}$ and $R_{2}(1-\mathrm{s}) / \mathrm{s}$ connected in parallel with the reactance magnetization $X_{M}$. The current required to produce a magnetic field is very large in an induction motor. This is due to the high value of reluctance of the air gap so that the reactance $X_{M}$ will be worth much less than the value of the resistance parallel to it. With a large lagging current, most of the voltage drop will occur in the inductive components of the circuit. Thus, the approximate equivalent input impedance is:

$\left|Z_{\text {eq }}\right|=\frac{V_{\emptyset}}{I_{1}, n_{1}} X_{1}+X_{M}$

Moreover, if $X_{1}$ can be determined in other ways, then the magnetizing reactance $X_{M}$ will also be known.

\subsection{Test}

Rotor resistance $R_{2}$ plays a critical role in the operation of the induction motor. Among others are $R_{2}$ determining the shape of the torque-velocity curve and the speed at which the 
maximum torque occurs. A standard motor test called the rotor held trial can determine the total motor resistance (this experiment will be described in the next section). However, this experiment is only intended to determine the total resistance. To determine accurately, it is necessary to know the magnitude so that it can be obtained by subtracting the total resistance by the resistance.

There is an experiment to determine $R_{1}$ whose value is independent of $R_{2}, X_{1}$ and $X_{2}$. This experiment is called the DC Test/Experiment. This is done by connecting the stator winding of the induction motor to a DC voltage. Since the current is DC current, no voltage is induced in the rotor circuit; thus, no current will flow. In addition, at DC current, the reactance of the motor is zero. Thus, the only current limiting the motor is the stator resistance, and therefore the magnitude of the resistance can be determined [10]. The basic circuit for this DC experiment is shown in picture 3 .

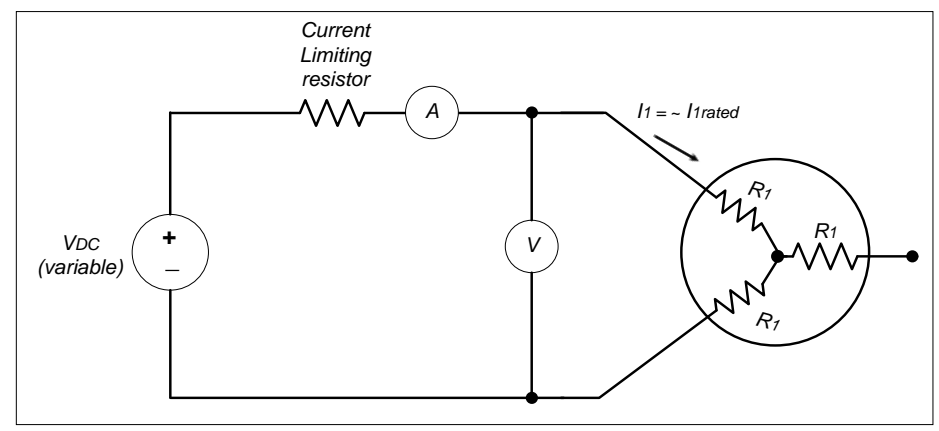

Picture 3. Experimental circuit for testing DC resistance

This picture shows a DC power supply connected to two of the three Y-connected terminals of an induction motor. To perform this test, the current in the stator winding is set at the nominal value, and the voltage between the terminals is measured. The current in the stator winding is set to a nominal value to heat the windings to the same temperature at which the windings operate under normal conditions (remember, winding resistance is a function of temperature).

The current in picture 3 flows through the two windings, so the total resistance in the current path is $2 R_{1}$.

Therefore,

$2 R_{1}=\frac{V_{D C}}{I_{D C}} ; R_{1}=\frac{V_{D C}}{2 I_{D C}}$

With the value of $R_{1}$, the stator copper losses at no-load conditions can be determined, and the rotational losses can be obtained by subtracting the input power $\left(P_{i n}\right)$ at no-load condition with stator copper losses $\left(P_{S C L}\right)$.

\subsection{Blocked Rotor Test}

The third experiment that can be carried out on an induction motor to determine its circuit parameters is the blocked-rotor test / locked-rotor test. In this experiment, the rotor is held not to rotate, and the source voltage is connected to the motor, then measure the voltage, current, and power generated.

Figure 4 shows the wiring for the rotor held experiment. To carry out this held-rotor experiment, an AC voltage is connected to the stator, and the current flowing is adjusted to near the full load value. If the current is at full load value, measure the voltage, current, and power flowing to the motor. This experiment's equivalent circuit is shown in picture 4(b). Note that, since the rotor is stationary, slip $s=1$, and thus $R_{2} / s$ is exactly equal to $R_{2}$ (a very small value). Because of the small value of $R_{2}$ and $X_{2}$ is almost all the input current will flow through it, compared to the current flowing through $X_{M}$ which is much larger value. Therefore, the circuit under these conditions looks like a series combination of $X_{1}, R_{1}, X_{2}$, and $R_{2}$.

However, there is a problem with this experiment. In normal operation, the stator frequency is the line frequency of the power system $(50$ or $60 \mathrm{~Hz}$ ). The rotor frequency is also the same as the line frequency at starting condition. However, under normal operating conditions, the slip of most motors is only $2-4 \%$, and the resulting rotor frequency is in the range of $1-3 \mathrm{~Hz}$. This will cause a problem because the grid frequency does not represent the normal operating conditions of the rotor. To overcome this, a compromise value is usually taken, namely by using a frequency of $25 \%$ or less than the nominal frequency. [11].

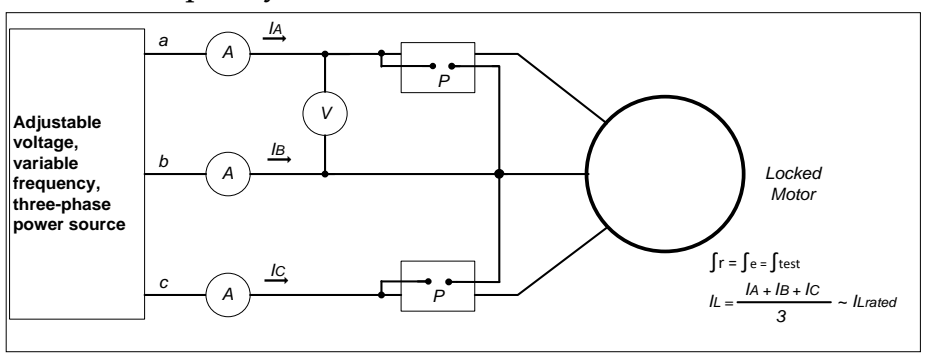

(a)

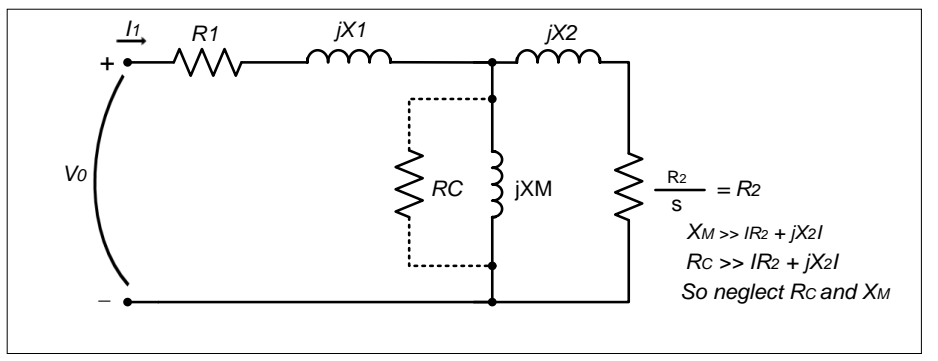

(b)

Picture 4. An experiment of blocked rotor for induction motor: (a) Experimental Circuit, (b) Motor Equivalent Circuit

After the power supply is connected to the motor, immediately adjust the amount of current flowing to approximately its nominal value, then measure the input power, voltage, and current before the rotor is subjected to excessive heating. The following equation gives the input power to the motor:

$P_{\text {in }}=\sqrt{3} V_{T} I_{I_{L}} \cos \theta$

so the power factor of the retained rotor can be obtained through the following equation:

$P F=\operatorname{Cos} \theta=\frac{P_{\bar{i}}}{\sqrt{3} V_{T} I_{I_{L}}}$

The total impedance of the motor circuit at these conditions are:

$\left|Z_{L R}\right|=\frac{V_{\emptyset}}{I_{1}}=\frac{V_{T}}{\sqrt{3} I_{L}}$

And the total impedance angle is $\theta$. Therefore,

$Z_{L R}=R_{L R}+j X_{L R}^{\prime}$ 
$Z_{L R}=\left|Z_{L R}\right| \operatorname{Cos} \theta+j\left|Z_{L R}\right| \operatorname{Sin} \theta$

Blocked rotor resistance $R_{L R}$ is equal to:

$R_{L R}=R_{1}+R_{2}$

While the blocked rotor reactance $X_{L R}^{\prime}$ is equal to:

$X_{L R}^{\prime}=X_{1}^{\prime}+X_{2}^{\prime}$

Where $X_{1}^{\prime}$ and $X_{2}^{\prime}$ are the stator and rotor reactance at the test/experimental frequency, respectively.

The rotor resistance $R_{2}$ can now be obtained by the following equation:

$R_{2}=R_{L R}-R_{1}$

where $R_{1}$ is determined by the DC experiment. The total reactance of the rotor with respect to the stator can also be obtained. Since reactance is directly proportional to frequency, the total equivalent reactance at its normal operating frequency can be obtained as follows:

$X_{L R}=\frac{f_{\text {rated }}}{f_{\text {terst }}} X_{L R}^{\prime}=X_{1}+X_{2}$

Unfortunately, there is no simple way to separate the contributions of the stator and rotor reactances from one another. Over the years, experience has shown that motors of certain types of design have a certain ratio between their stator and rotor reactance.

Table 1. Methods based on experience and practice (rule of thumb) to determine the amount of stator and rotor reactance.

\begin{tabular}{llc}
\hline \hline \multirow{2}{*}{ Rotor design } & \multicolumn{2}{c}{$\mathrm{X}_{1}$ and $\mathrm{X}_{2}$} \\
& \multicolumn{2}{c}{ as a function from } \\
\cline { 2 - 3 } & $\mathrm{X}_{1}$ & $\mathrm{X}_{2}$ \\
\hline Rotor winding & 0,5 & 0,5 \\
Design A & 0,5 & 0,5 \\
Design B & 0,4 & 0,6 \\
Design C & 0,3 & 0,7 \\
Design D & 0,5 & 0,5 \\
\hline \hline
\end{tabular}

To perform the above three tests using SIMULINK on MATLAB 2021b on a given induction motor model and compare the results with the given induction motor experimental parameters.

\section{Result and Discussion}

The induction motor parameters are given experimental results for the SIMULINK simulation studies. Type is threephase motor induction, wye-connected, squirrel-cage.

Power rated: $P_{\text {rat }}=7.460 \mathrm{~W}$

Stator voltage rated: $V_{s, \text { rat }}=220 \mathrm{~V}$

Frequency rated: $f_{\text {rat }}=50 \mathrm{~Hz}$

Number of poles: $P=6$

Stator resistance: $R_{s}=0.2943 \Omega / \mathrm{ph}$

Stator leakage reactance: $X_{l s}=0.524 \Omega / p h$

Rotor resistance referred to stator: $R_{r}=0.156 \Omega / \mathrm{ph}$

Rotor leakage reactance referred to stator: $X l r=0.279 \Omega / \mathrm{ph}$

Magnetizing reactance: $X_{m}=15.457 \Omega / \mathrm{ph}$

Mass moment of inertia of the rotor: $J m=0.4 \mathrm{~kg} \cdot \mathrm{m}^{2}$

Coefficient of friction: $C_{f}=0.062$

\subsection{Simulink Implementation of DC Test}

As a consequence of the DC current flowing through the stator winding, no voltage is induced in the rotor circuit, and the reactance of the motor is 0V [12]. Show figure 5 illustrate this test simulation.

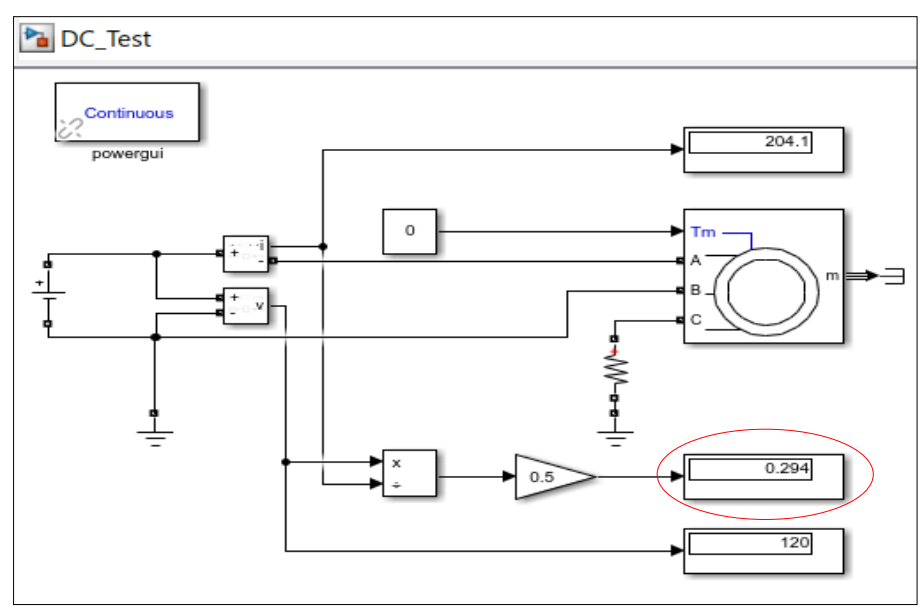

Picture 5. Simulation Diagram of DC Test

The DC test for the motor was carried out at SIMULINK on the MATLAB 2021b simulation software, and the data obtained were used in the calculations below.

$R_{1}=\frac{V_{D C}}{2 \cdot I_{D C}}=\frac{120}{2 \times 204.1}=0.2939 \Omega$

Table 2. Result of the DC test with errors

\begin{tabular}{ccccc}
\hline $\begin{array}{c}\text { DC Voltage } \\
(\mathrm{V})\end{array}$ & $\begin{array}{c}\text { DC Current } \\
(\mathrm{A})\end{array}$ & $\begin{array}{c}\text { Actual } \\
\text { Value }\end{array}$ & $\begin{array}{c}\text { Calculated } \\
\text { Value }\end{array}$ & $\begin{array}{c}\text { Error } \\
\text { Value }\end{array}$ \\
\hline 120 & 204.1 & $0.2943 \Omega$ & $0.2939 \Omega$ & $0.13 \%$ \\
\hline
\end{tabular}

\subsection{Simulink Implementation of Blocked Rotor Test}

This is done by applying zero speed to the motor and reading input of electrical power, current, and voltage [13]. Figure 6 illustrates this test simulation.

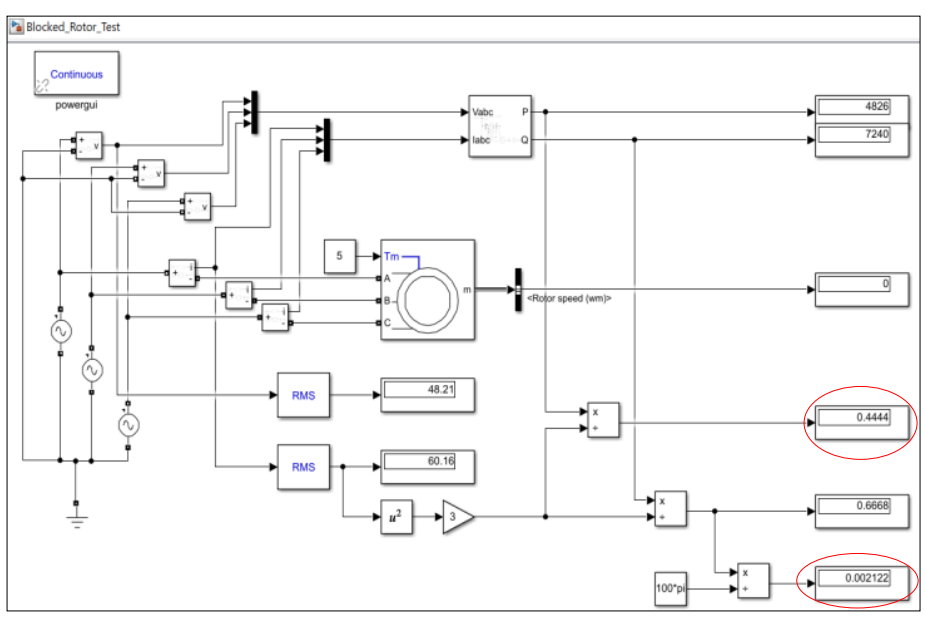

Picture 6. Simulation Diagram of Blocked Rotor Test

The values obtained from the blocked rotor test simulation at rated frequency is given in the table below and a formulae 
are used to calculate the blocked rotor test parameters $\left(\mathrm{Rr}_{\mathrm{r}} \mathrm{X}_{\mathrm{s}}\right.$ and $\mathrm{X}_{\mathrm{r}}$.

$$
\begin{aligned}
& R_{e}=\frac{P}{3 \cdot I_{L}^{2}} \\
& R_{e}=\frac{4826}{3 \cdot 60.16^{2}}=\mathbf{0 . 4 4 4 4} \Omega \\
& R_{e}=R_{1}+R_{2}^{\prime} \\
& R_{1}=\text { stator resestance from dc test } \\
& 0.44448=0.2939+R_{2}^{\prime} \\
& R_{2}^{\prime}=R_{r}=0.15058 \Omega \\
& X_{e}=\frac{Q}{3 \cdot I_{L}^{2}} \\
& X_{e}=\frac{7240}{3 \cdot 60.16^{2}}=0.66681 \Omega \\
& X_{e}=\frac{0.66681 \Omega}{100 \times p i}=\mathbf{0 . 0 0 2 1 2 ~} \mathbf{H} \\
& X_{e}=X_{1}+X_{2}^{\prime}
\end{aligned}
$$

\begin{tabular}{|c|c|c|c|c|c|c|c|c|}
\hline \multirow{2}{*}{$\begin{array}{l}\text { Current } \\
1 \varnothing(\mathrm{A})\end{array}$} & \multicolumn{2}{|c|}{ Power $3 \varnothing$} & \multicolumn{2}{|c|}{ Actual Value } & \multicolumn{2}{|c|}{$\begin{array}{c}\text { Calculated } \\
\text { Value }\end{array}$} & \multicolumn{2}{|c|}{$\begin{array}{c}\text { Error } \\
\text { Value (\%) }\end{array}$} \\
\hline & $\mathrm{P}(\mathrm{W})$ & $\mathrm{Q}$ (Var) & $\operatorname{Re}(\Omega)$ & $\mathrm{Xe}(\mathrm{H})$ & $\operatorname{Re}(\Omega)$ & $\mathrm{Xe}(\mathrm{H})$ & $\operatorname{Re}$ & $\mathrm{Xe}$ \\
\hline 60.16 & 4826 & 7240 & 0.4503 & 0.00213 & 0.4444 & 0.00212 & 1.31 & 0.37 \\
\hline
\end{tabular}

It is rather difficult to isolate the leakage reactance $\left(X_{1} \& X_{2}^{\prime}\right)$. Thus, for all practical purposes assumed to be equal.

$X_{1}=X_{2}^{\prime}=X_{e} / 2$

$X_{1}=X_{2}^{\prime}=\frac{0.00212 \mathrm{H}}{2}=0.001061 \mathrm{H}$

$X_{1}=X_{2}^{\prime} \approx X_{s}=X_{r}=0.001061 \mathrm{H}$

Table 3. Result of the blocked rotor test with errors

\subsection{Simulink Implementation of No-Load Test}

A-rated and balanced ac voltage at the rated frequency is applied when the stator is operating at no load, and the input power, voltage, and phase current are calculated [13]. Show figure 7 . To illustrate this test simulation.

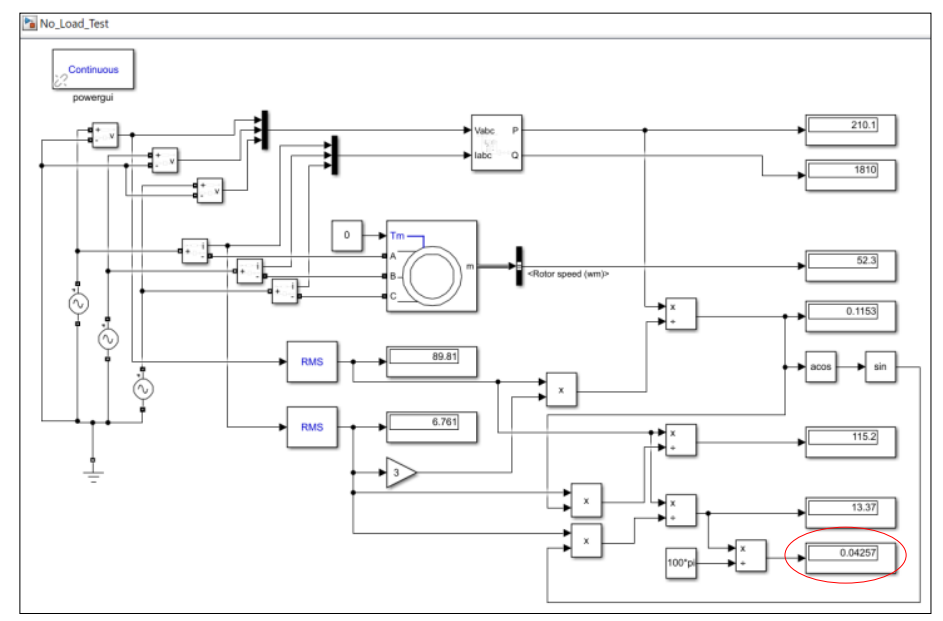

Picture 7. Simulation Diagram of No-Load Test

The values obtained from the no-load test simulations at the rated frequency and voltage are given in the table below, and different formulas are used to calculate the parameters $\left(\mathrm{X}_{\mathrm{M}}\right)$.
$P_{1 \emptyset}=\frac{P_{3 \emptyset}}{3}=\frac{210.1}{3}=70.033$ Watt

$P_{10}=I_{10} \cdot V_{10} \cdot \operatorname{Cos} \theta$

$\cos \theta=\frac{P_{1 \theta}}{V_{10} \times I_{10}}$, is power factor at no load

$\cos \theta=\frac{70.033}{89.81 \times 6.761}=0.11534$

$A \operatorname{Cos}(0.11534)=1.455216$

$\operatorname{Sin} \theta=0.993328$

$I_{C}=I_{10} \cdot \operatorname{Cos} \theta$, is core loss current

$I_{C}=6.761 \times 0.11534=0.77981374 \mathrm{~A}$

$R_{C}=\frac{V_{1 \emptyset}}{I_{C}}$, is core loss reistor

$R_{C}=\frac{89.81}{0.77981374}=115.1685 \Omega$

$I_{M}=I_{10} \cdot \operatorname{Sin} \theta$, is magnetization current

$I_{M}=6.761 \times 0.993328=6.715890608 \mathrm{~A}$

$X_{M}=\frac{V_{1 \emptyset}}{I_{M}}$, is magnetization reactance

$X_{M}=\frac{89.81}{6.715890608}=13.3727 \Omega$

$X_{M}=\frac{13.3727}{100 \times p i}=\mathbf{0 . 0 4 2 5 8 8} \boldsymbol{H}$

Table 4. Result of the no-load test with errors

\begin{tabular}{cccccccc}
\hline \hline $\begin{array}{c}\text { Voltage } \\
1 \varnothing(\mathrm{V})\end{array}$ & $\begin{array}{c}\text { Current } \\
1 \varnothing(\mathrm{A})\end{array}$ & $\begin{array}{c}\text { Power } \\
(\mathrm{W})\end{array}$ & $\begin{array}{c}\text { Power } \\
(\text { Var })\end{array}$ & $\begin{array}{c}\text { Power } \\
\text { Factor }\end{array}$ & $\begin{array}{c}\text { Actual } \\
\text { Value }\end{array}$ & $\begin{array}{c}\text { Calculated } \\
\text { Value }\end{array}$ & $\begin{array}{c}\text { Error } \\
\text { Value }\end{array}$ \\
\hline 89.810 & 6.761 & 210.1 & 1810 & 0.1153 & $0.041 \mathrm{H}$ & $0.042 \mathrm{H}$ & $0.38 \%$ \\
\hline \hline
\end{tabular}

\section{Conclusion}

Simulink in MATLAB 2021b simulation model of induction motor testing is carried out to obtain equivalent circuit parameters per phase of a three-phase induction motor.

Each Power System Block (PSB)/Simulink model is described and compared with the corresponding experimental setup.

Circuit parameters obtained from the simulation results are compared with those obtained from the hardware experiments.

The error studies show that MATLAB 2021b coupled with PSB (Power System Block)/Simulink is a good simulation tool for modelling induction motor tests and evaluating steadystate characteristics of three-phase induction motors.

\section{Acknowledgment}

P3M State Polytechnic of Sriwijaya (P3M-POLSRI) funded and supported this research. Thanks to the engineering team of Bukit Energy Service Terpadu, Ltd for helping to provide experimental data for induction motor in the completion of the research.

\section{References}

[1] IEEE Standard Test Procedure for Polyphase Induction Motors and Generators, IEEE Std. 112, 2004.

[2] Piromthum, P.; Kunakorn, A., (2003), Study of Starting 
Current Due to a Group of Induction Motor Using an Aggregation Model, Power Electronics an Drive System, PEDS 2003. The Fifth International Conference on, Volume 2, 17-20 Nov 2003, page 1054-1057.

[3] A Simple Approach To Induction Machine Parameter Estimation IMECS Maria-INCZE IoanIovTechnical University Of Cluj-Napoca, Romania: Workshop On ELECTRICAL MACHINES' PARAMETERS Technical University Of Cluj-Napoca, 26th Of May 200173.

[4] Chomat, M. Electric Machines and Drives. InTech Publisher, Croatia, February 28th 2011.

[5] Jonathan Kimball Experiments 7-8, Induction Machines. Curators of the University of Missouri, August 31, 2020.

[6] D.P. Kothari I.J. Nagrath. Electric Machines. McGraw Hill Education (India) Private Limited, New Delhi, 2018.

[7] Pedra, J. Estimation of Typical Squirrel-cage Induction Motor Parameter for Dynamic Performance Simulation, Generation Transmission and Distribution, IEE Proceeding, volume 153, 16 Maret 2006, hal 137-146.

[8] Anthony Z., Erhaneli Erhaneli and Busran Busran, (2017). A New Equivalent Circuit of The Three-Phase Induction Motor (Case Studies: Current and Power Factor of The Motor), ARPN Journal of Engineering and Applied Sciences (2017).

[9] Seung-Ki Sul. Control of Electric Machine Drive Systems 1st Edition, IEEE Press Series on Power and Energy Systems Book 55, Jun 9, 2011.

[10] Selek M., Terzioglu H., (2017). Determination of Equivalent Circuit Parameters of Induction Motors by Using Heuristic Algoritms, SUJEST, v.5, n.2, 2017 ISSN: 2147-9364 (Electronic).

[11] Theodore Wildi. Electical Machines, Drives and Power System (6th Edition), Pearson Prentice Hall, 2006.

[12] Hanselman, Duane Littlefield, Bruce Jozep Edyanto. MATLAB-Bahasa Komputasi Teknis. Penerbit ANDI, Yogyakarta, 2000.

[13] Adrian Biran (2022). MATLAB for Engineers, Retrieved January 24, 2022. 